\title{
La regulación de participación. El caso de la consulta previa en Colombia, Perú y Chile*
}

Robinson Sánchez Tamayo**

Recepción: 30 de julio de 2017 Aprobación: 12 de octubre de 2017

\section{RESUMEN}

La tensión entre neoliberalismo y derechos humanos en América Latina ha servido como caldo de cultivos de nuevas categorías de análisis como el concepto de Estado constitucional regulador, que surge en un contexto de desarrollo económico volcado en la producción de materias primas y la consolidación constitucional de un discurso de los derechos, en los que las cortes constitucionales han asumido un importante protagonismo. Este documento explica cómo se ha desarrollado este proceso en la regulación de la consulta previa en Colombia, Perú y Chile, para demostrar la permanente interacción entre ramas del poder público, especialmente de las cortes, y de discurso de los derechos con el de la regulación basada en la eficiencia.

Palabras claves: Consulta Previa, Estado Regulador, Estado Regulador Constitucional, Participación.

\section{INTRODUCCIÓN}

La tensión entre neoliberalismo y derechos humanos en América Latina ha generado toda una literatura en la región que ha posibilitado el surgimiento de nuevos

* El presente manuscrito es producto del proyecto de investigación: "La regulación de participación: el caso de la consulta previa en Colombia, Perú y Chile" en el marco del programa del Doctorado en Derecho en la Universidad de los Andes, Bogotá-Colombia. DOI: http://dx.doi.org/10.15332/s1909-0528.2018.0001.03

** Abogado de la Universidad de Antioquia-Colombia. Magíster en Derecho de la Universidad de los Andes, Bogotá - Colombia y candidato a Doctor en Derecho de la Universidad de Los Andes, Bogotá - Colombia. r.sanchez48@uniandes.edu.co 
marcos analíticos en el derecho como el neoconstitucionalismo, la incorporación en el derecho constitucional de conceptos como el "buen vivir", o el surgimiento de nuevos conceptos como el de Estado constitucional regulador. Este último surge en un contexto de desarrollo económico volcado en la producción de materias primas y la consolidación constitucional de un discurso de los derechos; en dicho contexto las cortes constitucionales han asumido un importante protagonismo. Este documento explica cómo se ha desarrollado este proceso en la regulación de la consulta previa en Colombia, Perú y Chile, para demostrar la permanente interacción entre ramas del poder público, especialmente de las cortes, y de discurso de los derechos con el de la regulación basada en la eficiencia.

Este artículo busca describir cómo se han desarrollado las características del Estado Constitucional Regulador en los tres países estudiados. Para ello, se revisó la jurisprudencia constitucional sobre la materia en los tres países hasta 2013 (fecha de cierra de la etapa de recolección de información), y la literatura sobre esta. También se realizaron entrevistas a funcionarios públicos con responsabilidades en el proceso de realización de la consulta previa, y a miembros de centros de investigación en derechos humanos, con la idea de contar con diferentes enfoques sobre el fenómeno.

Con dichos insumos se encontró que, si bien cada país ha vivido circunstancias sociales particulares, la regulación de la consulta previa se originó gracias al reconocimiento de la incorporación de esta figura en el ordenamiento constitucional interno, entendiéndola como un elemento constitutivo de otros derechos constitucionales (como el de la participación). Y como resultado de lo anterior, los tribunales constitucionales jugaron un papel fundamental en los esfuerzos de regulación, los cuales se crearon en el marco de un discurso de los derechos de las comunidades que interactúa permanentemente con el discurso de la eficacia en los proyectos de desarrollo. Sin embargo, es necesario precisar que en los tres países analizados las Cortes no han jugado el mismo papel en la definición de políticas públicas y que, en ese sentido, el Tribunal Constitucional chileno, por ejemplo, es más cauto que la Corte Constitucional colombiana; pero aun así en los tres países es posible identificar algún tipo de medida de sus tribunales en reconocer la inserción del discurso de los derechos humanos al momento de establecer criterios de regulación de la consulta previa 
para proteger a los pueblos indígenas, aunque se afectaran intereses económicos muy poderosos.

\section{La idea de la Regulación de la participación en Colombia, Perú y Chile}

No es una novedad afirmar que los debates constitucionales en América Latina, caracterizados por la tensión entre neoliberalismo y derechos humanos (Larraín, 1997; Santos y Rodríguez, 2007; Gargarella, 2013) han implicado nuevos desafíos a la idea tradicional de Estado regulador ${ }^{1}$. Concepto que ha sido entendido como la preservación estatal de la función de regulación de la prestación de servicios de interés público, que por mucho tiempo estuvieron reservados al Estado, pero en el que hoy actúan actores de diversa naturaleza, tal y como ocurre, por ejemplo, con la prestación de los servicios de televisión, agua, etc. (Majone, 1997; Prats y Comany, 1998; Sánchez y Villegas, 2001; Valencia, 2004; Matés-Barco, 2010).

Uno de estos desafíos es la ampliación de dicha noción a nuevas áreas de regulación como el medio ambiente o la seguridad alimentaria, en los que ya se identifica la existencia de entidades reguladoras en la región (Jordana y Levi-Faur, 2005). Pese a que estos autores consideran "la creación de autoridades reguladoras como el sello distintivo de la transformación del Estado como proveedor de servicios, en un Estado regulador (véase Majone, 1997)", también identifican otros cuatro procesos que se relacionan con el avance de este concepto y que sugieren una concepción más amplia de este. Dichos procesos son: 1) la privatización, 2) el establecimiento de agencias especializadas que ejercen un control regulador sobre entidades empresariales en áreas muy diversas, a menudo reconocidas como autoridades reguladoras independientes, 3) la formalización y codificación de mecanismos de aplicación de la ley en general y de la regulación en particular que operaban de manera informal, y 4) la proliferación

$1 \mathrm{Al}$ respecto es importante anotar que "entre las deliberaciones contemporáneas en las ciencias sociales y la ciencia jurídica en América Latina se encuentran cuestionamientos sobre la realización plena o parcial del Estado moderno, y relacionada con esta discusión se encuentra la implementación de la democracia y de la ciudadanía" (Llano, 2017, p. 210). 
de mecanismos de regulación, "metarregulación" y autorregulación reforzada (Jordana y Levi-Faur, 2005, p. 13 y ss.).

En un sentido similar, en la compilación realizada por Dubash y Morgan (2013) sobre el surgimiento del Estado regulador del sur se plantean dos puntos importantes. Primero, se habla de la posibilidad de usar el término "gobierno regulador" en lugar de "Estado regulador", debido a que aquel está empezando a ser más utilizado y "refleja mejor nuestra atención sobre cómo las instituciones reguladoras interactúan con otras instituciones para dar forma a patrones de gobierno"2 (Dubash y Morgan, 2013, p. 29). Segundo, los autores también se refieren a la amplia incidencia que han tenido las Cortes de países sureños en la regulación e implementación de diversas materias, lo que genera la necesidad de concebir una noción amplia de Estado regulador.

Pero el centro de estos desafíos es que dichos servicios también son entendidos como derechos, en ese sentido, como señala Urueña (2013), el Estado regulador que ha germinado no se limita a la regulación de agencias independientes que buscan corregir fallas del mercado, sino que también asume un compromiso más amplio con la adjudicación de derechos y la implementación de políticas redistributivas. Así propone el concepto de Estado regulador constitucional, que se caracteriza porque: 1) la regulación es la Constitución, por ende, las agencias reguladoras independientes adquieren un carácter instrumental en la implementación de los mandatos regulatorios constitucionales; 2) utiliza la interacción entre esas agencias y las cortes como su punto de partida, y 3) este Estado se constituye en un espacio donde el lenguaje de los derechos interactúa con el lenguaje de la regulación basada en la eficiencia, estableciendo un diálogo integrado por el discurso estándar de la regulación y por el del neoconstitucionalismo (Urueña, 2013, p. 24).

A partir de este concepto, Urueña presenta esta nueva dimensión de la regulación como "una plataforma para la realización de los derechos humanos, y no solo como

2 "We considered using the term 'regulatory governance' in place of 'regulatory state', since the former is obtaining growing currency and better reflects our own Attention to how regulatory institutions interact with other institutions in shaping patterns of governance". 
un instrumento para alcanzar una mayor eficiencia” (Urueña, p. 13); por ello resulta de especial utilidad, como marco para comprender el papel desempeńado por algunos tribunales y gobiernos de América Latina en el desarrollo y realización del derecho a la consulta previa, inserto en las jurisprudencias domésticas gracias al discurso de los derechos humanos movilizado por la Organización Internacional del Trabajo (OIT), la Organización de Naciones Unidas (ONU) y el Sistema Interamericano de Derechos Humanos (SIDH). Lo anterior resulta aplicable principalmente en Colombia, donde la Corte Constitucional ha jugado un papel protagónico en la regulación de este derecho, ya sea regulando la consulta previa como tal: qué es, cómo se hace, cuáles son los presupuestos que deben cumplirse para que sea constitucional. $\mathrm{O}$ interviniendo directamente en casos concretos para señalar los comportamientos de las instituciones estatales implicadas, regulando así las conductas de estas.

Algo similar ha ocurrido en Perú y Chile, en ambos países los tribunales constitucionales y ordinarios, los parlamentos y los gobiernos han regulado el derecho a la consulta previa, en un intento de incorporar los estándares internacionales de protección de los derechos humanos, en una lógica que podríamos ubicar en el concepto de Estado Regulador Constitucional. Y aunque se reconoce que no son los únicos países que han avanzado en la misma senda, se considera que sus casos permiten ilustrar adecuadamente los ejercicios de regulación de la consulta previa.

Con ello, se plantea que las cortes constitucionales, en materia de consulta previa, han sido "reguladoras receptivas", lo que supone que se trata de sujetos para los cuales no hay mejores o más óptimas soluciones reguladoras, solo soluciones que responden mejor que otras a las configuraciones plurales de soporte y oposición que existen en un momento particular de la historia (Ayres \& Braithwaite, 1995). Esta caracterización de los tribunales constitucionales de Colombia, Perú y Chile —aunque de algunos más que otros - obedece a que estos se vieron en la necesidad de acudir a soluciones reguladoras en materia de consulta previa según los casos específicos que abordaban, y atendiendo a circunstancias sociales e internacionales específicas del momento. 


\section{LA REGULACIÓN DEL DERECHO A LA CONSULTA PREVIA eN Colombia}

La consulta previa entra en escena en Colombia a partir de la Constitución Política de 1991. Si bien es cierto que el nuevo texto constitucional no plasmó este derecho de manera explícita, sí reconoció en distintos artículos su existencia, así la de derechos de las comunidades étnicas ${ }^{3}$ en el país (ver artículos 1, 7, 8, 70 y 330 de la Constitución). De manera paralela, mediante la Ley 21 de 1991, Colombia ratificó el Convenio 169 de 1989 de la oit. Por consiguiente, este tratado, por ser de derechos humanos y haber sido ratificado por Colombia mediante una ley aprobada por el Congreso, pasó a ser parte integral de la Constitución misma ${ }^{4}$. Lo cual resulta de sumo interés si consideramos que esta característica le ha dado competencia a la Corte Constitucional para pronunciarse sobre la consulta previa, en tanto garante de la Constitución y protectora de los derechos fundamentales.

De ahí que el primer aspecto vital sobre consulta previa que reguló la Corte Constitucional fue otorgarle su carácter de derecho fundamental. Ello a partir de la sentencia SU-039 de 1997 (M.P. Antonio Barrera Carbonell). Para ello, la Corte interpretó en conjunto el artículo 40 de la Constitución Política sobre participación ciudadana con el Convenio 169 de la oiT, y desde ahí empezó a tratar la consulta previa como un derecho fundamental ${ }^{5}$. Este primer paso es esencial cuando se habla de consulta previa en Colombia, pues calificarla como un derecho fundamental implicó que cualquier ley que regule la consulta previa debía tramitarse en el Congreso como una ley estatutaria y no como una ley ordinaria. Esto, en cierta medida, podría leerse como un obstáculo para que la consulta previa se regule mediante legislación, en la medida en que el trámite que deben surtir las leyes estatutarias es más complejo que el de las leyes ordinarias. En este sentido, este factor puede considerarse como un elemento que disuade al Estado de regular la consulta previa mediante legislación,

3 En Colombia, las comunidades étnicas incluyen pueblos indígenas, comunidades afrocolombianas o comunidades negras, y comunidades ROM o "gitanas".

4 Así se ha reconocido, por ejemplo, en las siguientes sentencias de la Corte Constitucional: Sentencia SU-039 de 1997. M.P. Antonio Barrera Carbonell; Sentencia T-880 de 2006. M.P. Álvaro Tafur Galvis; Sentencia T-745 de 2010. M.P. Humberto Antonio Sierra Porto, y Sentencia C-030/08. M.P. Rodrigo Escobar Gil.

5 Ver por ejemplo las sentencias SU-383 de 2003 (M.P. Álvaro Tafur Galvis) y T-376 de 2012 (M.P. María Victoria Calle Correa). 
lo que indirectamente ha conducido a que sea la Corte Constitucional quien debe continuar regulando la materia.

Un segundo punto sumamente importante que reguló la Corte Constitucional en materia de consulta previa fue el determinar en qué casos esta es procedente. Para ello, la Corte se basó en los artículos 6 y 7 del Convenio 169 de la oit. Estos dos artículos, en mayor medida el sexto, señalan que los gobiernos deben consultar a los pueblos interesados siempre que haya medidas legislativas o administrativas que puedan afectarlos directamente. Con base en lo anterior, la Corte Constitucional introdujo en su jurisprudencia la noción de afectación directa. En distintos $\operatorname{casos}^{6}$ ha aclarado la Corte que es obligatorio y necesario que se consulte previamente a comunidades étnicas cuando exista una medida administrativa o legislativa que los pueda afectar directamente. Esta noción se mantiene hoy en día en la jurisprudencia ${ }^{7}$.

Aunado a lo anterior, la Corte Constitucional no se ha limitado a señalar que la consulta previa procede cuando existe afectación directa en términos generales, sino que además ha determinado elementos que permiten identificar dicha afectación. De manera más específica, y especialmente en los casos que involucran el desarrollo de un proyecto (p. ej., la construcción de una carretera o explotación de un recurso), la Corte ha sido reiterativa en cuanto a que las comunidades étnicas se ven afectadas directamente de distintas formas, y no solo cuando están presentes en el área de desarrollo del proyecto. Es decir, la noción de afectación que ha desarrollado la Corte Constitucional no se limita a una noción de "ocupación"8.

Así, con base en normas constitucionales y disposiciones del Convenio 169 de la OIT, la Corte reguló dos aspectos esenciales de la consulta previa con comunidades étnicas, los cuales no era posible identificar en legislación o decretos. Estos aspectos esenciales fueron: 1) la determinación de que la consulta previa es un derecho fundamental, y 2) la aclaración de que la consulta previa debía tomar lugar siempre que existieran medidas administrativas o legislativas que los afectaran directamente. La

6 Ver, por ejemplo, las sentencias SU-383 de 2003 (M.P. Álvaro Tafur Galvis) y la T-880 de 2006 (M.P. Álvaro Tafur Galvis).

7 Ver, por ejemplo, la Sentencia C-1051 de 2012 (M.P. Luis Guillermo Guerrero Pérez).

8 Un caso claro de esto es el de la Sentencia T-745 de 2010 de la Corte Constitucional de Colombia. 
determinación, o regulación, de estos aspectos era imperioso realizarla, en aras de amparar los derechos de las comunidades étnicas.

Ahora bien, gracias a la introducción de la noción de afectación directa, la Corte ya había dejado claro cuándo procedía la consulta previa. Sin embargo, en los casos específicos que llegaban a conocimiento de la Corte Constitucional era posible identificar que tampoco había claridad sobre la manera en que la consulta debía realizarse. Pues no existía norma alguna que ilustrara los pasos que debían seguirse para realizar una consulta previa compatible tanto con la Constitución Política como con el Convenio 169 de la orT.

Por consiguiente, la Corte Constitucional se vio obligada a regular también los pasos y aspectos esenciales que debía caracterizar una consulta previa. En su jurisprudencia se plasmaron varias, tales como: 1) que la consulta previa no consiste únicamente en reuniones informativas $\left.{ }^{9}, 2\right)$ que la consulta debe realizarse con los representantes de las comunidades étnicas $\left.{ }^{10}, 3\right)$ que debe existir un proceso previo "pre-consultivo" para determinar las bases del resto del procedimiento a seguir ${ }^{11}$, y 4) que debe haber presencia de la Procuraduría General de la Nación y la Defensoría del Pueblo durante el proceso $^{12}$.

Estos elementos señalados por la Corte Constitucional son los que hoy en día rigen la realización de la consulta previa, y los cuales no se encontraban en ninguna norma hasta el año 2013 en que el presidente de la República expidió la Directiva Presidencial No. 10 de 2013. En esta directiva se recogieron todas las reglas creadas por la Corte Constitucional en su jurisprudencia para la realización de la consulta previa. Debe destacarse que sobre la efectividad de esta directiva presidencial aún es muy pronto pronunciarse.

9 Al respecto, podemos leer la Sentencia SU-039 de 1997 de la Corte Constitucional de Colombia, cuyo. M.P. Antonio Barrera Carbonell.

10 Aquí podemos ver las sentencias C-891/02 y C-030/08 de la Corte Constitucional de Colombia.

11 Ello lo podemos observar, por ejemplo, en la Sentencia T-737/05 de la Corte Constitucional de Colombia.

12 Ello lo podemos observar, por ejemplo, en la Sentencia T-129 de 2011 de la Corte Constitucional de Colombia. 


\subsection{El Estado regulador en Colombia en materia de consulta previa con comunidades étnicas}

Con base en todo lo anterior, es posible observar que la reguladora de la materia es la Corte Constitucional. Todo lo relativo a la consulta previa, incluyendo la caracterización como derecho fundamental, ha sido determinado por la Corte Constitucional como respuesta a las necesidades de las comunidades étnicas, y en razón de la ausencia de regulación normativa concreta por parte de los demás poderes estatales. Así, la Corte es claramente un "regulador receptivo" en el sentido que se planteó al inicio, ya que su manera de regulación es mediante la configuración de soluciones que respondían adecuadamente a la problemática sobre la materia: que tanto el Estado como empresas privadas omitían consultar a las comunidades étnicas y, por consiguiente, amenazaban gravemente sus condiciones de vida.

Adicionalmente, es posible visualizar también los elementos del Estado constitucional regulador. Por un lado, la regulación de la consulta se realiza con base en la Constitución. Valga recordar que no es solo según normas explícitas del texto constitucional, sino también según la cláusula de apertura que contiene el artículo 93, según el cual el Convenio 169 de la ort es parte de la Constitución misma.

Por otra parte, el lenguaje de derechos es evidente. Lo más interesante sobre esto es, además, que justamente el caracterizar la consulta previa como un derecho fundamental es lo que da pie para que la Corte continuara y profundizara la regulación de la materia. Con dicha caracterización, la Corte casi que se otorgó a sí misma la facultad de regular todos los aspectos relativos a la consulta.

Además, es clara también la interacción entre las Cortes y las entidades gubernamentales. Valga recordar que no existe una agencia reguladora independiente enfocada en la consulta previa. No obstante, las órdenes de la Corte inciden directamente en el comportamiento de las entidades estatales relacionadas a la consulta: principalmente el Ministerio del Interior y, según el caso, el Ministerio de Medio Ambiente, el Ministerio de Transporte, o cualquier otro.

Por último, debe señalarse lo siguiente. Si bien esta regulación de la consulta previa por parte de la Corte Constitucional colombiana ha sido determinante para la 
protección de los derechos de las comunidades étnicas, también plantea una problemática. El que la regulación haya sido prácticamente toda por vía jurisprudencial ahora limita la posibilidad de cristalizarlo todo en una ley. Primero porque, como ya se señaló, no se trata de una ley ordinaria, sino de una ley estatutaria que requiere un trámite más largo.

Segundo, y más importante aún, existe una problemática debido a la noción de afectación directa y la manera en que, según la Corte, debe surtirse la consulta. Según la Corte - y el Convenio 169 de la orT-, toda medida legislativa o administrativa que afecte directamente a las comunidades étnicas debe ser consultada. Con esto en mente, en tanto una ley que regule específicamente la consulta previa ciertamente afecta a las comunidades, cualquier ley sobre la materia debe consultarse. Es más, lo que debe consultarse es el proyecto de ley, atendiendo a que la consulta debe ser previa. Aunado a esto, debido a que la consulta previa debe realizarse con cada comunidad étnica según su cultura ${ }^{13}$, la consulta debe ser casi que individual con cada una. Así, la posibilidad de que se expida una ley estatutaria sobre consulta previa, debidamente consultada con cada una de las comunidades étnicas existentes en Colombia, es sumamente complicado.

En este orden de ideas, la regulación por parte de la Corte Constitucional ha sido buena y garantista. Sin embargo, también ha generado un bloqueo en cuanto a la posibilidad de cristalizar todas las características de la consulta en una Ley.

\section{La regulación del derecho a la consulta previa en Perú}

En Perú la consulta previa con comunidades étnicas ${ }^{14}$ se incorporó en la Constitución gracias al Tribunal Constitucional. Pues aunque el Convenio 169 se ratificó en 1995, se veía como una declaración no vinculante, hasta que, después del

13 Podemos leer con detenimiento la Directiva Presidencial No. 10 de 2013, la cual juntó todas las reglas de la Corte Constitucional sobre consulta previa para crear una Guía.

14 Denominadas por su contexto comunidades campesinas, rondas campesinas, comunidades nativas y comunidades no contactadas. 
"baguazo"15, el Tribunal consideró a la consulta previa como una concreción del derecho a la participación política, económica, social y cultural consagrado en el numeral 17 del artículo 2 de la Constitución ${ }^{16}$ y exhortó al Congreso a desarrollar una Ley sobre la materia.

Sin embargo, cabe sostener que el mayor nivel de regulación en el Perú en materia de consulta previa son la Ley y su Reglamento, una diferencia sustancial con Colombia y con Chile. La Ley de Consulta Previa y el Reglamento señalan los aspectos básicos sobre la materia tales como a quién se debe consultar, en qué ocasiones, cuáles son las etapas de la consulta y las obligaciones de las entidades estatales. No obstante, en cuanto a si es necesario el consentimiento por parte de las comunidades consultadas en determinados casos, la Ley no es específica y remite a otras normas del ordenamiento jurídico. Por otra parte, en cuanto a la determinación de la consulta previa como un derecho fundamental, esto no aparece de manera explícita en la Ley, pero sí fue señalado por el Tribunal Constitucional en Sentencia N. ${ }^{\circ}$ 03343-2007-PA/TC, como se señala en el siguiente acápite.

Ahora bien, la existencia de normatividad no supone que entonces esta sea la única regulación existente sobre la materia. Según entrevista con la actual directora de Consulta Previa del Ministerio de Cultura en el Perú, fue posible determinar que el rol de dicha entidad se limita a articular y coordinar la consulta previa. Por consiguiente, la entidad no realiza la consulta, pero sí interviene de distintas maneras. Concretamente, la Dirección ha tomado la iniciativa de expedir ciertos lineamientos para materias específicas relacionadas con consulta previa, tales como cuál es el procedimiento de petición y cuál es la manera en que se recoge información social durante el proceso de consulta previa.

Lo anterior demuestra un nivel de interlocución entre el Congreso, el Ejecutivo y el Tribunal Constitucional en la regulación de la consulta previa que no ha desaparecido con la expedición de dicha normatividad. Un ejemplo de ello es que las normas

15 Según manifestó la que era su directora en la entrevista para esta investigación, tiene funciones de articulación y coordinación, pero que ha tomado la iniciativa de expedir ciertos lineamientos para materias específicas relacionadas con consulta previa, tales como cuál es el procedimiento de petición y cuál es la manera en que se recoge información social durante el proceso de consulta previa.

16 Así lo podemos ver en la Sentencia 03343-2007-PA/TC del Tribunal Constitucional del Perú. 
no señalan aspectos como a quién se debe consultar, en qué ocasiones, cuáles son las etapas de la consulta y las obligaciones de las entidades estatales, los cuales fueron abordados por el Tribunal Constitucional en las Sentencias N. ${ }^{\circ}$ 03343-2007-PA/ TC, N. ${ }^{\circ}$ 0022-2009-PI/TC y 05427-2009-PC/TC. Estas tres sentencias constituyen la base reguladora del Tribunal Constitucional sobre el derecho a la consulta previa.

\subsection{El Estado regulador constitucional en el Perú en materia de consulta previa con comunidades étnicas}

Con respecto a las características del Estado regulador constitucional, es posible identificar el protagonismo de la Constitución como fundamento de la regulación del derecho a la consulta previa, pese a la existencia de una normatividad específica al respecto y de que no existe una mención expresa de dicho derecho en el texto constitucional. Sin embargo, el desarrollo jurisprudencial del Tribunal Constitucional peruano ha sido claro en establecer que el Convenio 169 y, en particular, el derecho a la consulta previa con comunidades étnicas hace parte de su normatividad interna como concreción del derecho constitucional a la participación política. Y de ella se deriva la responsabilidad estatal de regular dicho derecho aunque, como lo reconoce el Tribunal, su protección no puede depender de la existencia o no de una ley previa de regulación, pues es un mandato constitucional.

En cuanto a la interacción entre agencias reguladores y las cortes, otra de las características del Estado regulador constitucional que se puede observar que, a pesar de la inexistencia de una entidad reguladora independiente como tal en materia de consulta previa, es posible identificar una interacción del Tribunal Constitucional peruano con el poder Legislativo y Ejecutivo, que en su concepto son los responsables de definir el proceso de regulación de este derecho. A tal punto que el Tribunal, en desarrollo de la función de cooperación entre las ramas del poder público, hace un llamado a la aprobación de ley de regulación del proceso de consulta previa conforme a los principios orientadores definidos en su jurisprudencia y con atención a los estándares internacionales de derechos humanos. Este proceso, sin embargo, es aún muy incipiente pues no es posible identificar una interacción dinámica entre esta Corte y las entidades responsables de desarrollar el proceso de consulta en el Perú. 
Sobre la interacción entre el lenguaje de los derechos y el lenguaje de la regulación basada en la eficiencia es posible identificar al menos dos características: 1) que la regulación del proceso de consulta previa con comunidades étnicas debe ser eficiente como garantía de protección del derecho a la consulta previa, 2) que dicho proceso debe realizarse con base en los principios orientadores establecidos por el Tribunal Constitucional con arreglo a los estándares internacionales de derechos humanos.

Con ello, al igual que en el caso chileno, se pueden identificar elementos que infieren el desarrollo de un Estado regulador constitucional en materia de consulta previa. Aunque, como se reconoció en las entrevistas, aún falta mucho camino por recorrer para observar el funcionamiento de esas prácticas reguladoras en el marco del discurso de los derechos en casos concretos de tensión entre intereses económicos propios de proyectos de desarrollo, y la protección de los derechos de las comunidades étnicas sobre sus territorios y su cultura. De ahí la preocupación por la cantidad de declaratorias de improcedencia de las acciones que han llegado al Tribunal Constitucional.

\section{La regulación del Derecho a la consulta previa en Chile}

La consulta previa en Chile es una figura de reciente desarrollo en comparación con otros países de la región, como Colombia. De hecho, el Convenio 169 de la OIT entró en vigencia apenas el 15 de septiembre de 2009. Aquí, como en Perú y Colombia, la implementación de dicho Convenio y, en particular, de los artículos relacionados con la consulta previa, se tornó problemática por la discusión política ${ }^{17}$ sobre la reglamentación de su proceso de realización. A tal punto que el debate sobre el mismo obligó a los dos últimos gobiernos del país, tanto al primero de Michelle Bachelet (hoy de nuevo presidenta) como al de Sebastián Piñera, a expedir decretos con el fin de regular la materia, ambos con bastantes problemas de implementación, como se explicará más adelante.

17 Entiéndase por política el término griego politeía, cuyo significado "hacía referencia a la organización gubernamental de la polis, en tanto que para el siglo xvi el término política se generalizó para hacer referencia a asuntos del Estado y al estudio de las cosas políticas" (Sánchez, 2016, p. 195). 
Sanhueza identifica como obstáculos para la efectividad de la consulta previa en Chile: 1) la débil protección de los derechos de los pueblos indígenas, 2) la desorientación provocada por el formalismo que caracteriza al sistema jurídico nacional, 3) el recelo implícito al sistema internacional de derechos humanos y 4) la carencia de una ley que regule la consulta previa de manera integral y conforme a los estándares internacionales de derechos humanos (Sanhueza, 2013, p. 220). Esta lectura es compartida por una funcionaria del Instituto Nacional de Derechos Humanos (INDH), que en la entrevista para este trabajo explica que en Chile no hay protección constitucional para los pueblos indígenas, pese a las diferentes iniciativas legislativas que ha habido al respecto ${ }^{18}$.

Este panorama resulta paradójico si se considera que, poco después de la transición a la democracia, se expidió la Ley 19.253, en 1993, que establece normas sobre protección, fomento y desarrollo de los indígenas y crea la Corporación Nacional de Desarrollo Indígena (Conadi). Según explicó la funcionaria del INHD, esta entidad se ha concentrado, principalmente, en el tema Mapuche y la devolución de tierras. Ello debido la importancia de este pueblo, que representa el $87 \%$ del 4,7\% población indígena del país, según el censo de $2002^{19}$.

Sin embargo, la regulación del proceso de reglamentación de la consulta previa estuvo presente en la agenda política de los dos últimos gobiernos chilenos. Michelle Bachelet expidió el Decreto Supremo 124 de 2009, pero luego fue derogado por el Decreto Supremo 66 de 2013, en el gobierno de Sebastián Piñera.

El Decreto Supremo 124 fue expedido ante el vacío de regulación del proceso de consulta previa, que acababa de entrar a la legislación interna con la entrada en vigencia del Convenio 169 de la oIT, el mismo día de su expedición, 15 de septiembre de 2009. Sin embargo, el mismo fue duramente cuestionado porque no fue consultado con los pueblos indígenas del país y porque ponía en riesgo el derecho a la

18 Entrevista a Diana Maquilón Tamayo.

19 Para ampliar podemos ver: http://www.ine.cl/canales/chile_estadistico/estadisticas_sociales_culturales/ etnias/ etnias.php. (última entrada diciembre de 2014). 
consulta previa al definir un proceso muy superficial de consulta y participación, con plazos de hasta de dos meses ${ }^{20}$.

Fue tan importante el rechazo al decreto por parte de las organizaciones sociales indígenas que el opositor Sebastián Piñera decidió asumir el compromiso político de derogarlo. En una serie de reuniones con representantes de esas comunidades se comprometió a formular una nueva reglamentación sobre la consulta previa. Según la funcionaria del INDH, el acuerdo se basaba en tres ejes: 1) regular el reconocimiento constitucional de los derechos de los pueblos indígenas, 2) constituir una nueva institucionalidad indígena distinta a la Conadi y 3) hacer una consulta para determinar cómo se debía desarrollar el proceso de consulta previa. Todo esto a cargo del Ministerio de Desarrollo Social (Antes Ministerio de Planificación Social), a cual estaba adscrita la Unidad de Asuntos Indígenas ${ }^{21}$.

El gobierno finalmente expidió el Decreto Supremo 66 de 2013, que derogaba el Decreto Supremo 124 de 2009. Sin embargo, este también fue cuestionado duramente por las organizaciones sociales indígenas que se separaron del proceso de concertación, al considerar que no se estaba realizando una consulta como lo había prometido el presidente Piñera sino, más bien, un proceso informativo sobre la expedición de la nueva regulación del proceso de consulta previa.

Además, el gobierno estaba formulando paralelamente una nueva institucionalidad ambiental, a través del Sistema de Evaluación de Impacto Ambiental (SEIA), con el Decreto 40 de 2012 en el cual el proceso de regulación de los proyectos de inversión quedaban sometidos a las nuevas superintendencias ambientales, pero de paso los sacaba del proceso de consulta previa que se reglamentaba en el Decreto Supremo 66 de 2013. Así los proyectos de desarrollo y con un alto impacto económico, que son los más sensibles en los procesos de consulta previa, quedaban sometidos a la regulación ambiental y no a la de consulta previa.

20 Esto no se compadecía con los términos que implica un proceso serio de estudio y análisis colectivo de las implicaciones de los proyectos de desarrollo en un territorio determinado, por ejemplo.

21 Más sobre ese proceso se puede ver en: http://www.consultaindigena.cl (última entrada diciembre de 2014). 
Según Sanhueza, la regulación de la consulta previa vigente hoy en Chile: 1) excluye a las municipalidades del deber de consulta; 2) excluye a los proyectos ingresados al SEIA, que constituyen el foco principal de judicialización del derecho a consulta previa, y 3) presenta confusiones en conceptos tan elementales como el derecho a participación y consulta previa generando limitaciones significativas (Sanhueza, 2013, p. 241). Críticas que recoge en su entrevista la funcionaria del INDH, para quien hoy se tienen dos instrumentos paralelos para realizar la consulta y ninguno de los dos cumple con los estándares internacionales de derechos humanos. Coincide el exrelator especial de la ONU para para el tema "considera que el título actual de la Propuesta y las menciones exclusivas al Convenio 169 de la OIT no engloban suficientemente el marco jurídico internacional que define la consulta a los pueblos indígenas y que vincula a Chile" (Anaya, 2012, p. $7^{22}$ ).

Por su parte, el Tribunal Constitucional chileno no ha desarrollado una fuerte jurisprudencia sobre le protección y regulación de la consulta previa. Este Tribunal tiene dos sentencias sobre la ratificación del Convenio 169 de la OIT. La primera por un requerimiento de inconstitucionalidad interpuesto en contra de dicho Convenio 169 por un grupo de diputados, Sentencia Rol 309-2000. La segunda, en abril de 2008, en desarrollo del control de constitucionalidad previsto en la Constitución chilena, Sentencia Rol 1050-08.

Estas sentencias disponen que: 1) el derecho a la consulta y el derecho a la participación, consagrados en los artículos $6^{\circ}$ y $7^{\circ}$ del convenio, son normas autoejecutables pues tratan de materias ya previstas por el ordenamiento jurídico interno, y 2) la consulta previa es un mecanismo de participación que no tiene carácter vinculante y, por tanto, no transgrede el principio de participación con igualdad que consagra el artículo $1^{\circ}$ de la Constitución chilena. Para Sanhueza, estas ideas

han servido tanto para tutelar este derecho en tribunales, así como para justificar prácticas estatales que en verdad no cumplen con los estándares de la consulta, como por ejemplo sostener que la participación ciudadana de la institucionalidad ambiental también cumple lo exigido por el derecho a la consulta previa (Sanhueza, 2013, p. 236).

22 ver: http://www.observatorio.cl/sites/default/files/biblioteca/comentarios_relator_anaya_propuesta_reglamento _consulta_gobierno.pdf (última entrada diciembre de 2014). 
Otro pronunciamiento importante de este Tribunal, en lo que respecta a la regulación de la consulta previa, es el control de constitucionalidad sobre la Ley de Pesca, Rol 2387-2013 y Rol 2388-13, acumulados en sentencia del 23 de enero de 2013. En la que se establece que "esa necesidad urgente de regular el procedimiento de consulta se debe hacer en el marco de los claros criterios establecidos respecto de su vigencia, jerarquía, naturaleza jurídica y características”, es decir: 1) se trata de una consulta diversa a la prevista en la ley indígena, 2) que no implica ejercicio de la soberanía, 3) que solo es una forma de recabar opinión, y 4) que no tiene carácter vinculante ni afecta las atribuciones privativas de las autoridades constitucionales (Corte Constitucional de Chile, 2013: considerando 14).

Sin embargo, en el caso chileno como la acción que protege derechos fundamentales —el denominado "recurso de protección” — se tramita vía la jurisdicción ordinaria, las cortes de apelaciones y la Corte Suprema han jugado un papel más activo en la regulación de la consulta previa, aunque no de manera ordenada y sistemática. De hecho, la funcionaria del INDH se quejó en la entrevista de la dispersión de las sentencias de estas cortes, y señaló la dificultad de acceder a ellas.

Sanhueza explica el protagonismo de estas cortes en la judicialización del derecho a la consulta previa por la inexistencia de una normativa que lo regule, sometiendo al ejecutivo a la experimentación con sus decisiones administrativas, las cuales están sometidas al control judicial de estas cortes, que han actuado como contencioso administrativo, principalmente en materia ambiental, en lo que se refiere a la aprobación o rechazo de un proyecto de inversión con alguna afectación ambiental. Lo que en materia de consulta previa, se traduce en la evaluación de si se cumplieron o no los mecanismos de participación que ofrece la legislación vigente. Según desarrolla,

el trabajo jurídico que han realizado los jueces, por tanto, se materializa en un juicio sobre el deber legal que recae en los órganos de la administración y, en el fondo, si éstos ejercieron sus competencias en actos cuya discrecionalidad ya está tazada por el legislador (Sanhueza, 2013, p. 243) 23.

23 Algunas de las sentencias de la Corte Suprema de Justicia de Chile que se pueden ver son las siguientes: Sentencia Rol 2.840-2008, Sentencia Rol 2683-2010, Sentencia Rol 1.219-2009. 
Con base en ello, la Corte Suprema estableció una jurisprudencia tendiente a establecer cuando se aprobó o no una Resolución de Calificación Ambiental (RCA) sin consulta previa. Esto se lleva a cabo, según evidencia Sanhueza, cuando la autoridad administrativa tramita la aprobación de un proyecto como Estudios de Impacto Ambiental (EIA) y no como Declaración de Impacto Ambiental (DIA), con la idea de desconocer el derecho a la participación de las comunidades afectadas previstas en el último. Con este proceso, la jurisprudencia ha venido "transitando de una interpretación que subsume la consulta previa al procedimiento de participación ciudadana del SEIA, a una actual interpretación que exige una participación ciudadana bajo los estándares del Convenio 169", en desarrollo de lo previsto en la legislación ambiental, específicamente en algunos de los efectos, características o circunstancias que genera el proyecto según el artículo 11 de la Ley 19.300, que exige, por ejemplo, la participación ciudadana cuando un proyecto se desarrolla en un territorio indígena (Sanhueza, 2013, p. 244 y ss.).

Así, este tribunal ha dado pasos importantes en la tutela del derecho a la consulta previa. Aunque no esté consagrado como un derecho fundamental específico en la Constitución Política chilena, los avances en materia constitucional sobre la relación entre este derecho y el derecho constitucional a la participación, y los desarrollos sobre participación ciudadana han servido como fundamento del papel regulador de este derecho de las cortes en Chile, pese al vacío de una legislación que lo desarrolle conforme a los estándares internacionales de derechos humanos.

\subsection{El Estado regulador en Chile en materia de consulta previa con comunidades étnicas}

Lo anterior permite afirmar que el poder judicial también ha cumplido un papel fundamental en la regulación de la consulta previa en Chile, pues como ocurrió en los otros dos países estudiados, ha sido el Tribunal Constitucional quien insertó en el derecho doméstico el derecho a la consulta previa con fundamento en lo establecido en el Convenio 169 de la oit y sus desarrollos en el SIDH.

$\mathrm{Al}$ igual que en el caso colombiano, esta función reguladora de los órganos judiciales se ha desarrollo en virtud de la protección constitucional tanto en Tribunal 
Constitucional (en el ejercicio del control de constitucionalidad) como en la Corte Suprema (como juez de tutela de segunda instancia), aunque en Colombia ambas funciones recaen en la Corte Constitucional. Y con el caso peruano comparte la discusión política de una normativa de regulación por fuera de las instancias judiciales, que en el caso peruano recayó en el Legislativo y en el caso chileno en el Ejecutivo, pero se diferencian en el mayor protagonismo que ha asumido la Corte Suprema en la suspensión de proyectos de desarrollo en virtud de la tutela del derecho a la consulta previa.

Ello constituye el discurso fundamental de lo que se ha conocido como Estado Constitucional Regulador en el caso específico de la regulación del derecho a la consulta previa. Pues, por un lado, se ha establecido a la Constitución Política como fuente de la regulación de este derecho. Punto que en principio parece discutible, toda vez que no existe un mandato constitucional expreso que garantice el derecho a la consulta previa, y su regulación se ha dado más por la normatividad ambiental. Sin embargo, cabe anotar que el derecho a la consulta previa ha sido incorporado al derecho interno chileno en desarrollo del derecho constitucional a la participación ciudadana. Y segundo, que si bien la Corte Suprema ha garantizado este derecho conforme a lo establecido en la legislación ambiental, dicho trabajo se ha desarrollado en virtud de su función constitucional como juez de tutela. Lo que pone a la Constitución en el centro de ese ejercicio de regulación.

Sobre la interacción entre las agencias reguladoras y las cortes, vale la pena señalar que como en los casos previamente analizados, tampoco existe en Chile una entidad con dichas características. Pero lo que sí se ha podido determinar es un nivel de interacción entre la Corte Suprema, las cortes de apelaciones y las entidades que desarrollan proyectos de desarrollo, gracias a la función que tiene la jurisdicción ordinaria de tutelar el derecho a la consulta previa conforme a la reglamentación ambiental chilena, en los términos arriba señalados. Especialmente cuando se ha intentado tramitar algunos proyectos de inversión como EIA y no como DIA, para evadir la obligación de realizar la consulta previa con comunidades étnicas aprovechando la doble reglamentación que existe en el país sobre este tipo de procesos.

Esta interacción ha permitido, de alguna manera, configurar un espacio donde el lenguaje de los derechos interactúa con el lenguaje de la regulación basada en la 
eficiencia. Pues cuando la jurisdicción ordinaria cumple el papel de juez de tutela para estudiar los actos administrativos ha servido como punto de contención de la omisión de la obligación de consultar utilizando la regulación ambiental que es más laxa al respecto para lograr mayor eficiencia, aunque dicha jurisprudencia no sea sistemática. Allí, según lo explicado por Sanhueza, es posible determinar que el papel cumplido por esta jurisdicción como control a los actos administrativos en materia ambiental y de participación ciudadana es un desarrollo, aunque incipiente, de ese espacio. Entendida la participación ciudadana no solo como un derecho consagrado en la Constitución Política del país, lo que ha servido como ruta de incorporación de los estándares internacionales de derechos humanos sobre consulta previa en el derecho doméstico chileno. Esto pese a que el trámite simultáneo de las dos reglamentaciones diferentes, la de la consulta previa y la ambiental, puso en riesgo la protección de este derecho en temas muy sensibles como los proyectos de desarrollo realizados por entidades descentralizadas.

Ello, al igual que en el caso chileno, permite identificar elementos que infieren el desarrollo de un Estado Regulador Constitucional en materia de consulta previa. Aunque como se reconoció en las entrevistas, al igual que en Perú y Colombia, aún falta mucho camino por recorrer, pues aún es necesario profundizar en el reconocimiento de estándares de derechos humanos en los procesos de consulta establecidos en los dos decretos supremos establecidos por el expresidente Sebastián Piñera.

\section{Conclusiones}

La regulación que se ha realizado en Colombia, Perú y Chile de la consulta previa con comunidades étnicas es un ejemplo de cómo se ha desarrollado el concepto de Estado constitucional regulador en la región. Esto, pues, ha permitido situar a las respectivas Constituciones en el centro del ejercicio de la regulación del proceso de consulta previa con comunidades étnicas. En la jurisprudencia de los tres países se encuentran referencias a la necesidad de que dichos procesos se realicen garantizado dicho derecho, que pese a no estar consagrado de forma expresa en ninguna de las tres cartas políticas, ha sido incorporado en estas como desarrollo de derechos fundamentales. Así, se ha configurado un escenario de interacción entre las tres ramas del poder 
público, con el fin de avanzar en la protección del derecho a la consulta previa en un marco de regulación basado en la eficiencia. Sin embargo, con excepción del caso colombiano, dicha interacción no ha sido sistemática, y a veces los pronunciamientos pueden parecer contradictorios. Ello puede explicarse por la ausencia de una entidad encargada de regular la consulta previa, aunque en los tres países se han constituido entidades asesoras u orientadoras del proceso. Al tiempo que se ha constituido un escenario de diálogo entre el discurso de los derechos y el de la eficiencia, pues en los tres países ha quedado establecido que la consulta previa con comunidades étnicas debe ser un derecho protegido, independientemente del modelo de regulación que se adelante sobre este. Esto puede resultar especialmente interesante considerando que los tres países tienen una importante vocación minera en sus economías, cuyos proyectos de desarrollo pueden entrar en tensión con la protección de los derechos de las comunidades étnicas.

\section{REFERENCIAS}

Ayres, I., \& Braithwaite, J. (1995). Responsive regulation: Transcending the deregulation debate. Oxford University Press on Demand.

Congreso de la República de Perú, Ley No. 29785.

Congreso de la República de Perú, Resolución Legislativa N. 26253.

Corte Constitucional de Colombia. (1997), Sentencia SU-039 de 1997. M.P.: Antonio Barrera Carbonell.

Corte Constitucional de Colombia. (1998). Sentencia T-762 de 1998. M.P.: Carlos Gaviria Díaz.

Corte Constitucional de Colombia. (2003). Sentencia SU-383 de 2003. M.P.: Álvaro Tafur Galvis.

Corte Constitucional de Colombia. (2006). Sentencia T-880 de 2006. M.P.: Álvaro Tafur Galvis.

Corte Constitucional de Colombia. (2008). Sentencia C-030 de 2008. M.P.: Rodrigo Escobar Gil. 
Corte Constitucional de Colombia. (2010). Sentencia T-745 de 2010. M.P.: Humberto Antonio Sierra Porto.

Corte Constitucional de Colombia. (2011). Sentencia T-693 de 2011. M.P.: Jorge Ignacio Pretelt Chaljub.

Corte Constitucional de Colombia. (2012). Sentencia T-1080 de 2012. M.P.: Jorge Ignacio Pretelt Chaljub.

Corte Constitucional de Colombia. (2012). Sentencia T-376 de 2012, M.P.: María Victoria Calle Correa.

Corte Suprema de Justicia de Chile. (2008). Sentencia Rol 2.840-2008.

Corte Suprema de Justicia de Chile. (2009). Sentencia Rol 1.219-2009.

Corte Suprema de Justicia de Chile. (2010). Sentencia Rol 2683-2010.

Dubash, N. K., \& Morgan, B. (Eds.). (2013). The rise of the regulatory state of the south: Infrastructure and development in emerging economies. Oup Oxford.

Galvis Patińo, M. C., Ramírez Rincón, Á. M. (2013). Digesto de Jurisprudencia Latinoamericana Sobre los Derechos de los Pueblos Indígenas a la Participación, la Consulta Previa y la Propiedad Comunitaria.

Gargarella, R. (2013). Dramas, conflictos y promesas del nuevo constitucionalismo latinoamericano. Anacronismo e irrupción, 3(4), 245-257.

Jordana, J., \& Levi-Faur, D. (2005). The diffusion of regulatory capitalism in Latin America: Sectoral and national channels in the making of a new order. The Annals of the American Academy of Political and Social Science, 598(1), 102-124.

Larraín, J. (1997). Modernidad e identidad en América Latina. Revista Universum, 12, 13-23.

Llano J. (2017). Construcción de ciudadanía en la América Latina del siglo xix: Una perspectiva constitucional. Revista Republicana. Núm. 22, Enero-Junio de 2017, pp. 209-230. Documento extraído el 1 de octubre de 2017 de http://ojs.urepublicana.edu.co/index. $\mathrm{php} /$ revistarepublicana/article/view/385/340

Majone, G. (1997). From the positive to the regulatory state: causes and consequences of changes in the mode of governance. Journal of public policy, 17(2), 139-167. 
Matés-Barco, J. M. (2010). Empresas, sociedad y servicios públicos: del Estado prestador del estado regulador. Documento extraído el 2 de octubre de https://dadun.unav. edu/bitstream/10171/5909/4/Empresa\%2c\%20sociedad\%20y\%20servicios\%20p\% C3\%BAblicos.\%20Del\%20Estado\%20prestador\%20al\%20Estado\%20regulador..pdf

Prats, J., y Comany, L. (1998). La construcción institucional de las capacidades regulatorias. Un tema clave de la nueva agenda del desarrollo. Instituciones y desarrollo, (1).

Presidencia de la República de Colombia, Decreto 1320 de 1998.

Presidencia de la República de Colombia, Directiva Presidencial No. 1 de 2010.

Presidencia de la República de Colombia, Directiva Presidencial No. 10 de 2013.

Presidencia de la República de Perú, Decreto Supremo No. 001-2012-MC.

Sánchez, G., y Carlos Andrés y Villegas Carrasquilla, L. (2001). Regulación de los servicios públicos: redefinición constitucional del Estadocolombiano. Un estudio crítico constitucional de las comisiones de regulación de los servicios públicos domiciliarios. En Barreto, A. (Coor.). Derecho constitucional. Perspectivas críticas. Universidad de los Andes, Legis. Bogotá.

Sánchez, P. (2016). Dimensiones de la política. Revista Principia Iuris. Julio-Diciembre 2016, 13(26), 193-212. Documento extraído el 2 de octubre de 2017 de http://revistas. ustatunja.edu.co/index.php/piuris/article/view/1142/1108

Sanhueza, C., y Cristián, L. (2013). La consulta previa en Chile: del dicho al hecho. Olea, H. Derecho y pueblo mapuche. Aportes para la discusión. Santiago de Chile: Centro de Derechos Humanos udp. Universidad Diego Portales.

Santos, B., y Garavito, C.A. R. (2007). El derecho, la política y lo subalterno en la globalización contrahegemónica.

Santos, B., y Rodríguez Garavito, C. (2007). El derecho y la globalización desde abajo. Hacia una legalidad cosmopolita. Barcelona: Anthropos Editorial.

Tribunal Constitucional de Chile. (2008). Sentencia Rol 1050 de 2008.

Tribunal Constitucional de Chile. (2013). Sentencia Rol 2387-2013.

Tribunal Constitucional de Chile. (2013). Sentencia Rol 2388-2013. 
Tribunal Constitucional del Perú, Sentencia 03343-2007-PA/TC.

Tribunal Constitucional del Perú, Sentencia 0022-2009-PI/TC.

Tribunal Constitucional del Perú, Sentencia 05427-2009-PC/TC.

Tribunal Constitucional del Perú, Sentencia 06316-2009-AA/TC.

Tribunal Constitucional del Perú, Sentencia 00023-2009-PI/TC.

Tribunal Constitucional del Perú, Sentencia 00025-2009-PI/TC.

Tribunal Constitucional del Perú, Sentencia 00027-2009-PI/TC.

Urueña, R. (2012). The rise of the constitutional regulatory state in Colombia: The case of water governance. Regulation \& Governance, 6(3), 282-299.

Valencia Agudelo, G. D. (2004). Metamorfosis del Estado: de empresario a regulador: El caso de los servicios públicos domiciliarios en Colombia. Ecos de Economía: A Latin American Journal of Applied Economics, 8(18), 7-32. 